\title{
Bone histology in young adult osteoporosis
}

\author{
ELLEN HILLS, C R DUNSTAN, S Y P WONG, R A EVANS \\ From the Metabolic Unit, Concord Hospital, Sydney, Australia
}

SUMMARY Bone histology was quantitated in 10 osteoporotic patients aged between 17 and 51 years and in six healthy subjects aged between 23 and 43 years. The osteoporosis was of varying aetiology and was clinically stable. All patients were given tetracycline before biopsy and double tetracycline labelling was used in seven patients. Bone forming and resorbing surfaces were defined by the presence of osteoblasts and osteoclasts, respectively, which were identified by histochemical techniques.

The associations between bone forming and resorbing surfaces were similar in patients and controls, though the range of values was wider in the patients than in the controls. Mineral apposition rate was normal in the osteoporotic patients, but there was a reduction in mineralising (tetracycline) surface, whether related to osteoid surface or to osteoblast surface. This did not indicate osteomalacia as the directly and indirectly measured mineralisation lag times were normal. The osteoid seams were thinner in osteoporotic patients than in controls.

The data suggest that osteoclast and osteoblast numbers were normal in this group of osteoporotic patients but that the metabolic activity of osteoblasts was impaired.

Acquired osteoporosis can only arise from an imbalance between bone resorption and formation, and the nature of this imbalance should be definable by quantitative bone histology. In the numerous histological studies of osteoporosis, however, the findings have varied between an increase in resorbing surface, ${ }^{1-7}$ a decrease in forming surface, ${ }^{6-12}$ or no detectable abnormality. ${ }^{1314}$ Most of these studies have identified bone resorption by crenated surface and formation by osteoid, and have not measured osteoblasts or osteoclasts; when control specimens have been included, they have often been taken after death.

In this report we describe bone histology in 10 relatively young patients with clinically stable osteoporosis and compare them with six healthy controls. Though the osteoporosis was of varying aetiology, and in seven the aetiology was unknown, they had in common the problem of a bone mass low enough to lead to pathological fractures. The histological techniques include histochemical stains to identify osteoclasts ${ }^{1516}$ and osteoblasts ${ }^{17}$ and tetracycline labelling to show mineralisation. ${ }^{17}$ In seven patients dynamic measurements of bone formation after double tetracycline labelling were also obtained.

\section{Material and methods}

The 10 patients all presented with pathological Accepted for publication 6 October 1988 fractures which included the vertebrae in all except case 3 (table 1). Mean (SD) age was 34 (10) years, range 17-51 years. Brief clinical details are shown in table 1 , and case 1 with idiopathic juvenile osteoporosis has previously been described in more detail. ${ }^{18}$ No patient admitted to excessive alcohol intake, had gastrointestinal disease, or a family history of pathological fractures. All patients had normal plasma concentrations of calcium and phosphate and alkaline phosphatase activities; 24 hour urinary calcium concentration was also normal $(2 \cdot 5-7 \cdot 5$ $\mathrm{mmol}$ ) in all patients. Parathyroid hormone (PTH) concentrations were measured in six patients by commercially available assays, using a predominantly carboxyterminal specific antibody and yielded normal results.

The controls comprised six healthy employees-five men, aged $32(8)$ years, range $23-43$ years. ${ }^{17}$

All patients took demeclocycline $1.2 \mathrm{~g}$ three days before biopsy, and seven (and the six controls) also took tetracycline hydrochloride $1.5 \mathrm{~g} 24$ days before biopsy. Each label was given over a period of about 12 hours.

\section{BONE BIOPSY SAMPLING}

In the controls and in eight patients this was taken from the posterior superior iliac spine, with an $8 \mathrm{G}$ Jamshidi needle $(20 \times 2 \mathrm{~mm} \text { core })^{19}$; transiliac samples were obtained with an RNOH trephine $(10 \times 5 \mathrm{~mm}$ core) from cases 1 and 8 . The values for 
Table 1 Clinical details

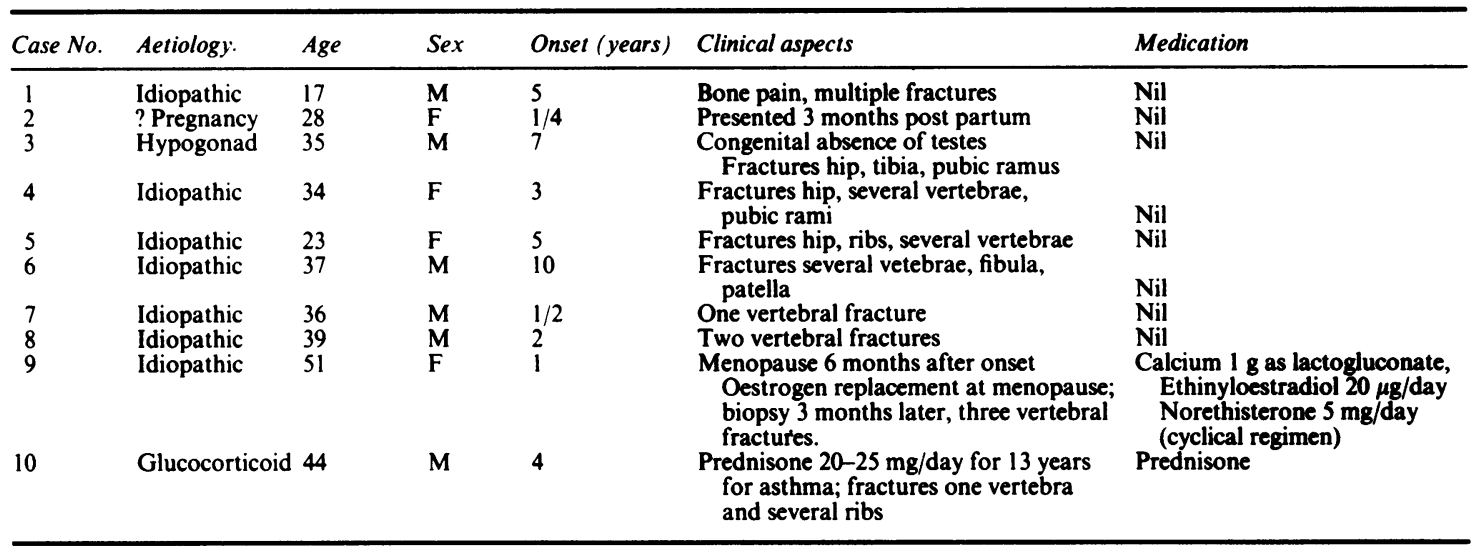

formation and resorption variables are similar from the two sampling sites. ${ }^{172}$

The sample was fixed in cold $10 \%$ formalin, $\mathrm{pH} 7 \cdot 0$, dehydrated in ethanol, and embedded in a methyl methacrylate-glycol methacrylate medium. ${ }^{15}$ Three consecutive sections were taken at each of two levels within the tissue block; a $5 \mu \mathrm{m}$ section for histochemical staining to demonstrate acid phosphatase activity ${ }^{15}$ a $7 \mu \mathrm{m}$ section mounted unstained for tetracycline fluorescence; and a $5 \mu \mathrm{m}$ section for pyronin staining to show ribonucleic acid. ${ }^{17} \mathrm{~A}$ total section area of at least $50 \mathrm{~mm}^{2}$ was measured. Toluidine blue was used as a counterstain for the first and third sections. Osteoclasts were identified by their red granular cytoplasm in the sections stained for acid phosphatase activity. ${ }^{15}$ Osteoblasts were defined as cells (plump or flat) forming a continuous lining on bone surfaces and showing intense cytoplasmic pyronin staining. ${ }^{17}$ Osteoid was defined as unmineralised matrix, visible when viewed at a magnification of $\times 100$ (objective $\times 6 \cdot 3$, numerical aperture $0 \cdot 16$ ). Polarised light was used to identify woven bone. A microscope with a camera lucida attachment was used to prepare a tracing (magnification $\times 100$ ) of the superimposed images of the three consecutive sections, and the tracings were quantitated with an $X-Y$ digitiser interfaced to a desk top computer. ${ }^{17}$

The methods of calculation have been described in detail previously, ${ }^{17}$ but some aspects should be explained here. Bone resorption was expressed as osteoclast count $/ \mathrm{mm}^{2}$ section area, and as resorbing surface (the percentage of bone surface actually in contact with osteoclasts). The two tetracyclines fluoresced with different colours so that it was possible to identify separately first and second markers. Tetracycline surface was measured only where second marker was present (thus some was single label and some double). Formation rate was determined by multiplying the tetracycline surface (second label) by the mineral apposition rate and dividing by the section area measured; it was thus expressed as $\mu \mathrm{m}^{2} / \mathrm{day} / \mathrm{mm}^{2}$ section area. The separation of double tetracycline markers and the width of overlying osteoid ("active" osteoid) were measured directly at $100 \mu \mathrm{m}$ intervals where both tetracycline and osteoblasts were present; the width of the remaining osteoid was measured in a similar manner. The directly measured mineralisation lag time was calculated as described by Sherrard et $a l,{ }^{21}$ by dividing osteoid width by mineral apposition rate using these data. The indirectly measured mineralisa-

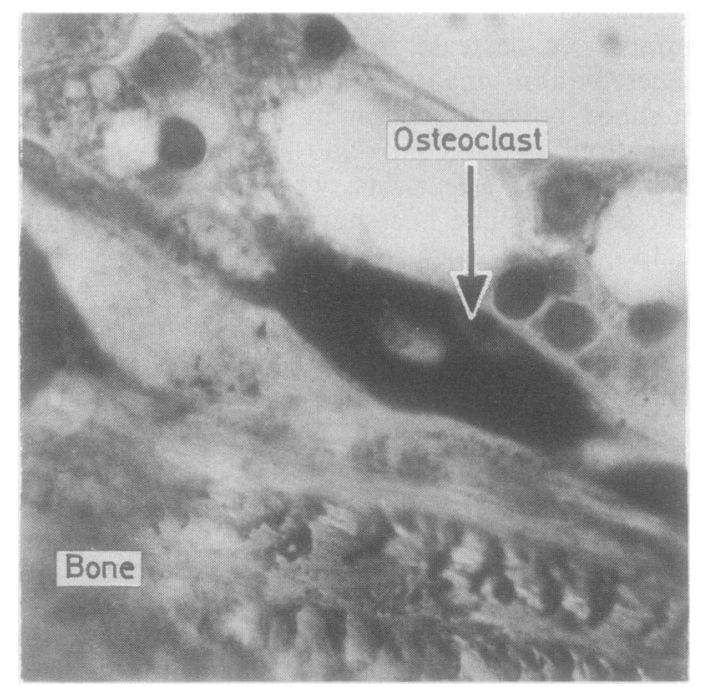

Fig 1 Undecalcified section of bone stained for acid phosphatase activity with toluidine blue counterstain. Osteoclasts are identified by their dark granular cytoplasm. reflecting high levels of acid phosphatase activity. (Green filter.) 


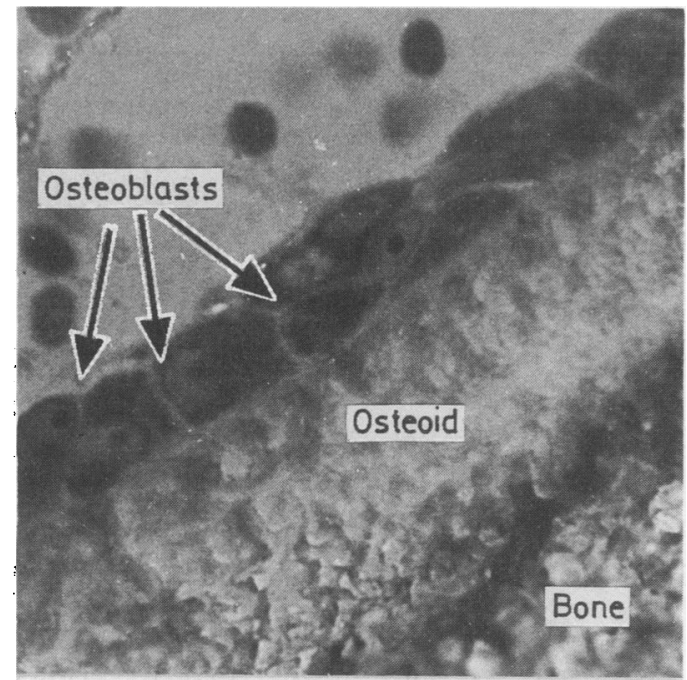

Fig 2 Undecalcified section of bone stained with pyronin and with toluidine blue counterstain. Osteoblasts are identifiable by their dark cytoplasm, reflecting the presence of ribonucleic acid. tion lag time was measured as described by Nielsen $e t$ $a l,{ }^{22}$ by dividing osteoid area by the bone formation rate. Resorption velocity was calculated by dividing the bone formation rate by resorption surface $(\mu \mathrm{m} /$ $\mathrm{mm}^{2}$ section area). ${ }^{17}$ This makes the assumption that bone formation and resorption are equal within the biopsy specimen. Mean wall thickness of trabecular basic structural units was measured as described by Lips et al. ${ }^{23}$

Statistical analysis was carried out using a PDP $11 / 23$ computer with the "Minitab" (Pennsylvania State University) program. Differences between groups were determined by one way analysis of variance, with log transformations carried out on data not showing a normal distribution. Correlations between variables were tested for significance by linear regression.

\section{Results}

The histological appearances of osteoclasts and osteoblasts, when stained by the histochemical technique, are shown in figs 1 and 2 . In two patients (cases

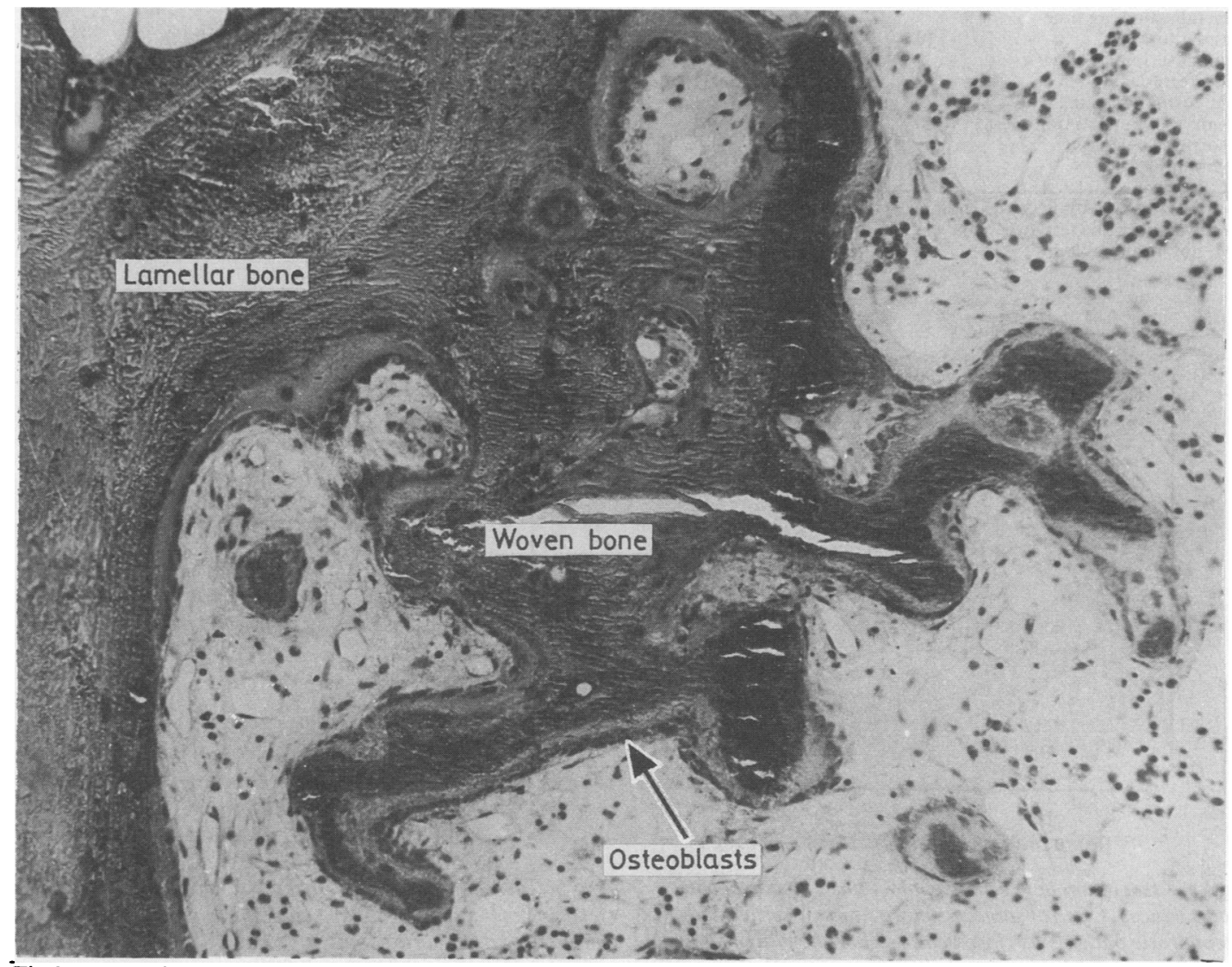

Fig 3 Area of woven bone with surrounding osteoblastic activity (case 2). Appearance is consistent with a healing microfracture. 
Table 2 Quantitative bone histology

\begin{tabular}{|c|c|c|c|c|c|c|c|c|c|c|c|c|}
\hline Case No & 1 & 2 & 3 & 4 & 5 & 6 & 7 & 8 & 9 & 10 & $\begin{array}{l}\text { Group } \\
\text { Mean (SD) }\end{array}$ & $\begin{array}{l}\text { Control } \\
\text { Mean }(S D)\end{array}$ \\
\hline $\begin{array}{l}\text { Static variables: } \\
\text { Bone area }(\% \text { section area) } \\
\text { Mean wall thickness }(\mu \mathrm{m}) \\
\text { Osteoid area }(\% \text { bone area }) \ddagger \\
\text { Osteoid surface }\end{array}$ & $\begin{array}{c}7 \cdot 4 \\
54 \\
2 \cdot 1\end{array}$ & $\begin{array}{l}9 \cdot 8 \\
64 \\
11 \cdot 3\end{array}$ & $\begin{array}{c}5 \cdot 7 \\
51 \\
4 \cdot 3\end{array}$ & $\begin{array}{c}5 \cdot 1 \\
55 \\
4 \cdot 4\end{array}$ & $\begin{array}{c}8 \cdot 3 \\
30 \\
3 \cdot 1\end{array}$ & $\begin{array}{c}10 \cdot 9 \\
47 \\
6 \cdot 9\end{array}$ & $\begin{array}{c}9 \cdot 4 \\
40 \\
8 \cdot 0\end{array}$ & $\begin{array}{l}14.9 \\
49 \\
1 \cdot 1\end{array}$ & $\begin{array}{l}17 \cdot 3 \\
48 \\
0 \cdot 1\end{array}$ & $\begin{array}{c}8.0 \\
39 \\
6.9\end{array}$ & $\begin{array}{l}9 \cdot 7(3 \cdot 9)^{*} \\
48(10) \\
4 \cdot 8(3 \cdot 5)\end{array}$ & $\begin{array}{l}17(4)^{*} \\
54(3) \\
3.8(2.5)\end{array}$ \\
\hline $\begin{array}{l}(\% \text { total surface }) \ddagger \\
\text { Mean osteoid width }(\mu \mathrm{m}) \\
\text { "Active" osteoid width }(\mu \mathrm{m}) \\
\text { Tetracycline surface }\end{array}$ & $\begin{array}{l}13 \\
15 \\
18\end{array}$ & $\begin{array}{l}33 \\
14 \\
19\end{array}$ & $\begin{array}{l}14 \\
12 \\
13\end{array}$ & $\begin{array}{l}10 \\
11 \\
18\end{array}$ & $\begin{array}{l}10 \\
14 \\
18\end{array}$ & $\begin{array}{l}20 \\
14 \\
18\end{array}$ & $\begin{array}{l}26 \\
14 \\
17\end{array}$ & $\begin{array}{r}3 \\
15 \\
26\end{array}$ & $\begin{array}{r}1 \\
10 \\
+\dagger\end{array}$ & $\begin{array}{l}22 \\
13 \\
18\end{array}$ & $\begin{array}{l}15(10) \\
13(2) \dagger \\
18(3)\end{array}$ & $\begin{array}{l}14(7) \\
16(1) \\
19(4)\end{array}$ \\
\hline $\begin{array}{l}\text { (\% total surface) } \ddagger \\
\text { Tetracycline surface }\end{array}$ & $7 \cdot 2$ & $16 \cdot 0$ & $4 \cdot 0$ & 0.7 & $2 \cdot 2$ & $8 \cdot 7$ & $12 \cdot 3$ & 0.9 & 0.2 & $14 \cdot 6$ & $6.7(6.0)$ & $8 \cdot 1(4 \cdot 1)$ \\
\hline $\begin{array}{l}\text { (\% osteoid surface) } \\
\text { Tetracycline surface }\end{array}$ & 55 & 48 & 28 & 7 & 21 & 44 & 48 & 30 & 22 & 66 & $37(18) \dagger$ & $62(14)$ \\
\hline $\begin{array}{l}(\% \text { osteoblast surface }) \ddagger \\
\text { Osteoblast surface }\end{array}$ & 157 & 63 & 83 & 54 & 58 & 91 & 85 & 45 & NM & 119 & $84(35)^{*}$ & $149(68)$ \\
\hline & $4 \cdot 6$ & $25 \cdot 6$ & $4 \cdot 8$ & $1 \cdot 3$ & $3 \cdot 8$ & $9 \cdot 6$ & $14 \cdot 5$ & $2 \cdot 0$ & 0 & $12 \cdot 3$ & $7.9(7.9)$ & $5.9(2.7)$ \\
\hline $\begin{array}{l}\text { (\% osteoid surface) } \\
\text { Resorbing surface }\end{array}$ & 55 & 78 & 33 & 13 & 37 & 48 & 56 & 66 & 0 & 56 & $44(24)$ & $45(17)$ \\
\hline $\begin{array}{l}(\% \text { to } \\
\text { Osteocl }\end{array}$ & $1 \cdot 3$ & 3.5 & 0.8 & $1 \cdot 0$ & $0 \cdot 3$ & $1 \cdot 2$ & 4.9 & 0.5 & 0 & 1.9 & $1.5(1.5)$ & $1.0(0.4)$ \\
\hline $\begin{array}{l}\left(\text { per } \mathrm{mm}^{2} \text { section area }\right) \ddagger \\
\text { Crenated surface }\end{array}$ & 0.5 & $2 \cdot 8$ & 0.3 & 0.6 & 0.2 & $1 \cdot 3$ & 3.0 & 0.5 & 0 & $1 \cdot 1$ & $1 \cdot 1(1 \cdot 2)$ & $1.0(0.5)$ \\
\hline ( \% total s & $11 \cdot 4$ & $11 \cdot 3$ & $5 \cdot 2$ & $9 \cdot 2$ & $4 \cdot 8$ & 5.9 & $20 \cdot 3$ & $8 \cdot 3$ & $9 \cdot 2$ & $12 \cdot 7$ & $9 \cdot 8(4 \cdot 6)$ & $7 \cdot 2(3 \cdot 2)$ \\
\hline $\begin{array}{l}\text { Dynamic variables: } \\
\text { Mineral apposition rate } \\
(\mu \mathrm{m} / \text { day }) 9 \\
\text { Mineralisation lag time }\end{array}$ & 1.4 & $0 \cdot 7$ & 0.6 & NM & $1 \cdot 1$ & $1 \cdot 2$ & 1.0 & NM & NM & $0 \cdot 8$ & $1.0(0.3)$ & $1.0(0.2)$ \\
\hline $\begin{array}{l}\text { direct (days) } \\
\text { Mineralisation lag time }\end{array}$ & 13 & 24 & 21 & NM & 25 & 14 & 16 & NM & NM & 21 & $19(5)$ & $18(3)$ \\
\hline $\begin{array}{l}\text { indirect (days) } \\
\text { Bone formation rate }\end{array}$ & 13 & 42 & 72 & NM & 49 & 28 & 27 & $\mathbf{N M}$ & NM & 21 & $36(20)$ & $33(17)$ \\
\hline $\begin{array}{l}\left(\mu \mathrm{m}^{2} / \text { day } / \mathrm{mm}^{2} \text { section area }\right)+\mathscr{} \\
\text { Resorption velocity } \\
(\mu \mathrm{m} / \text { day }) \neq \emptyset\end{array}$ & $\begin{array}{l}120 \\
6 \cdot 9\end{array}$ & $\begin{array}{r}266 \\
3 \cdot 7\end{array}$ & $\begin{array}{l}34 \\
3.0\end{array}$ & $\begin{array}{l}\text { NM } \\
\text { NM }\end{array}$ & $\begin{array}{l}52 \\
8 \cdot 5\end{array}$ & $\begin{array}{r}273 \\
8 \cdot 6\end{array}$ & $\begin{array}{l}283 \\
2 \cdot 7\end{array}$ & $\begin{array}{l}\text { NM } \\
\text { NM }\end{array}$ & $\begin{array}{l}\text { NM } \\
\text { NM }\end{array}$ & $\begin{array}{r}262 \\
7 \cdot 0\end{array}$ & $\begin{array}{r}180(110) \\
5.8(2.6)\end{array}$ & $\begin{array}{r}220(170) \\
8 \cdot 3(4 \cdot 1)\end{array}$ \\
\hline
\end{tabular}

*Different to controls $p<0.05 ; \uparrow$ different to controls $p<0.01 ; \ddagger \log$ transformed data used for $t$ test; $q n=7$ for these variables as cases 4,8 , and 9 received only one tetracycline label.

NM, not measurable.

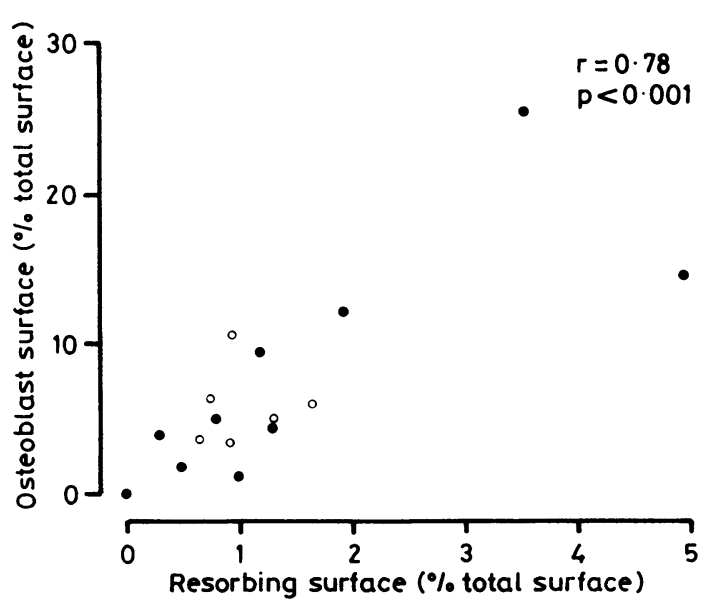

Fig 4 Association between osteoblast lined and osteoclast lined surfaces. Control subjects shown as open circles and osteoporotic patients as closed circles. For the patients alone, $r=0.81, p<0.01$.

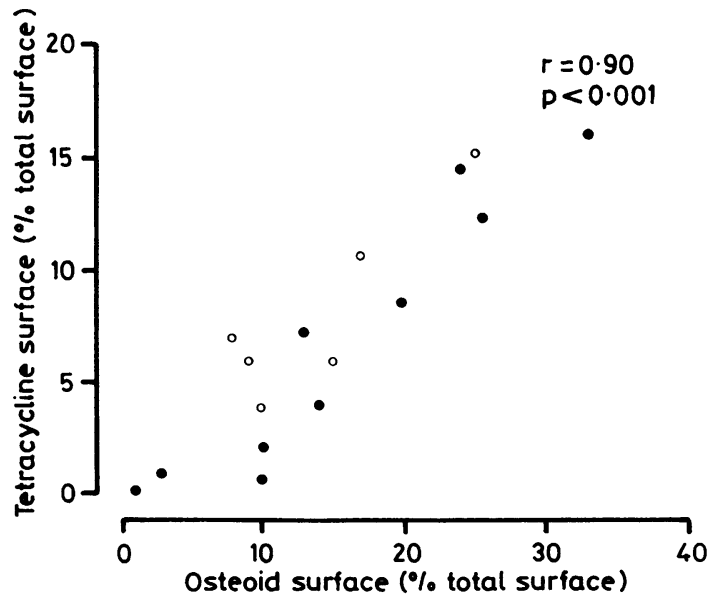

Fig 5 Association between osteoid surface and extent of tetracycline uptake. Control subjects are shown as open circles and osteoporotic patients as closed circles. For the patients alone $r=0.91, \mathrm{p}<0.001$. 


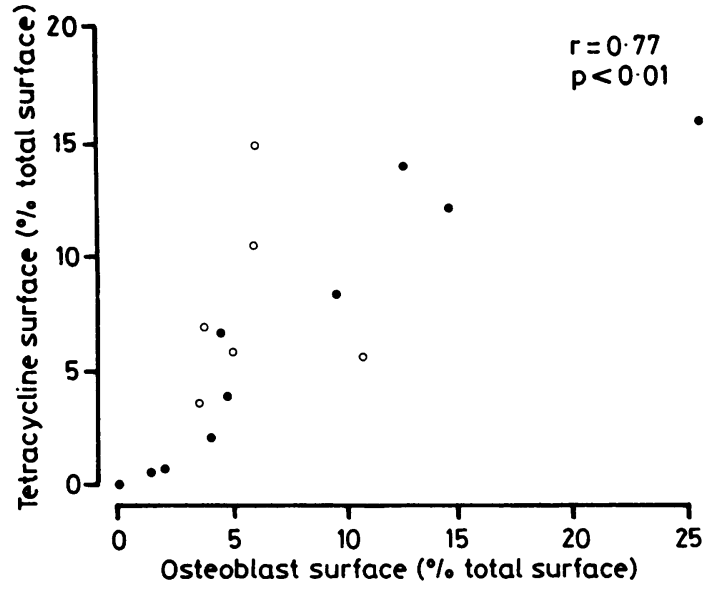

Fig 6 Association between osteoblast lined surface and the extent of tetracycline uptake. Control subjects are shown as open circles and osteoporotic patients as closed circles. For the patients alone, $r=0.92, p<0.001$.

1 and 2) sections contained an area of woven bone lined by osteoblasts and exhibiting intense tetracycline uptake (fig 3). This appearance is similar to that previously reported in healing microfractures. ${ }^{24}$

Quantitative bone histology is shown in table 2 . Trabecular bone area was less in patients than controls. Osteoclast count and resorbing surface varied from very low in case 9 who was taking oestrogens, to high in three patients ( related to pregnancy, induced by glucocorticoids, and one with idiopathic osteoporosis). Crenated surface did not correlate with resorbing surface and was high in only one patient. Mineral apposition rate and bone formation rate were within the normal range, though in the hypogonad male (case 3) they were slightly lower than in all of the controls. Mean wall thickness of bone structural units was below the normal range in three patients.

The high degree of correlation between forming and resorbing surfaces is shown in fig 4 , which includes both patients and controls. Though there was a wider range of values for patients than for controls, the relation between the two was similar in both groups. Surface labelled with tetracycline correlated with osteoid surface (fig 5) and with osteoblast surface (fig 6). Osteoblast surface also correlated with osteoid surface (fig 7). Though the labelled surface was similar in patients and controls, the ratio of tetracycline surface to both osteoid surface and osteoblast surface was lower in osteoporotic patients than in controls (table 2). The mean osteoid seam width was less in osteoporotic patients than in controls, and the direct and indirect mineralisation lag times were similar in patients and controls.

PTH concentrations, expressed as a percentage of

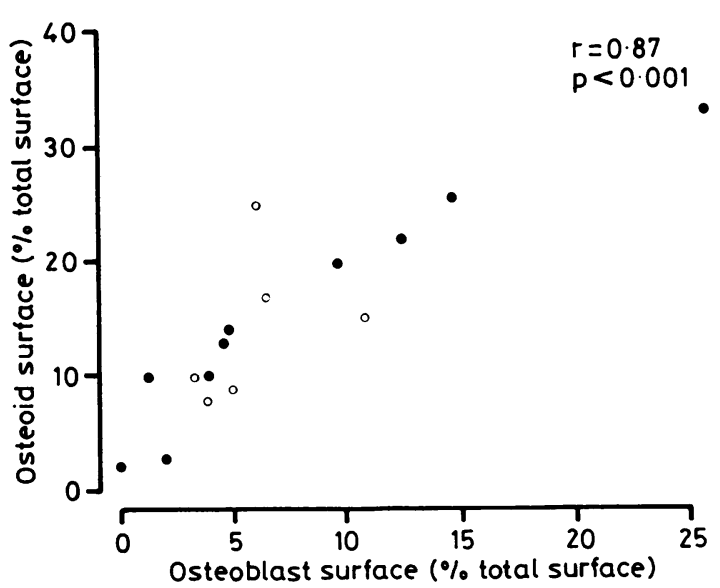

Fig 7 Association between osteoblast lined and osteoid lined surfaces. Control subjects are shown as open circles and osteoporotic patients as closed circles. For the patients alone, $r=0.95, p<0.001$.

the upper limit of normal, did not correlate with resorbing or forming surfaces. Case 9 , with the most inactive bone, had been taking calcium and oestrogens orally, but had a normal PTH. Of the two with the most active bone, case 1 was young and had a normal PTH concentration; PTH was not measured in case 7.

\section{Discussion}

The association between bone forming and resorbing surfaces was similar in patients and controls, though there was a wider range of bone activity in the patients. The zero values in case 9 probably reflected the action of oestrogen on bone and illustrate how this hormone could be expected to maintain but not increase bone mass. Large forming and resorbing surfaces were seen in case 2 (osteoporosis related to pregnancy) and in case 7 with idiopathic osteoporosis. Thus our data do not show the increased bone resorption or decreased bone formation reported in some previous studies. Our data also do not confirm the findings of Jackson et $a l,{ }^{12}$ who found a reduced mean osteoblast surface in eugonadal men $^{7}$ with osteoporosis, and an increased osteoblast surface in men with hypogonadism.

There was, however, a more subtle defect in bone formation. Though the osteoporotic patients had normal osteoblast numbers relative to osteoclasts, there was evidence of abnormal osteoblast function. Impaired mineralisation was shown by a reduction in the ratio of tetracycline surface to osteoblast surface, and, as previously reported in patients with postmenopausal osteoporosis, ${ }^{25}$ in the ratio of tetracycline surface to osteoid surface. This probably reflects an osteoblast defect, as the high correlation between 
tetracycline surface and osteoblast surface suggests that these cells initiate mineralisation. ${ }^{26}$ The defect is probably a reduction in the duration of osteoblast activity rather than a reduction in the rate of mineral deposition as the mineral apposition rate and directly measured mineralisation lag times were normal in our patients. Our findings thus differ from those of Parfitt et al," who reported a prolonged mineralisation lag time in older patients with postmenopausal osteoporosis. The life span of osteoblasts was not reduced as the osteoblast surface was normal relative to the osteoid surface. Thus in this heterogeneous group of patients there was a reduced level of osteoblast activity, causing delayed mineralisation of terminal osteoid seams and perhaps also reduced osteoid synthesis. In three patients (one with glucocorticoid osteoporosis, two with idiopathic osteoporosis) the low mean wall thickness of "bone structural units" ${ }^{23}$ was additional evidence of impaired bone formation.

These abnormalities of osteoblast function were of small degree but could have led to osteoporosis over a period of years. The abnormality might also be inherited and so have been present from birth. We have recently observed a low spinal bone mass in apparently healthy young adult relatives of patients with idiopathic or postmenopausal osteoporosis. ${ }^{27}$ This suggests that osteoporosis may often result, at least in part, from a failure to develop a normal bone mass i. early adult life, with clinical disease being precipitated by bone loss-for example, following the menopause or glucocorticoid administration. This low "peak bone mass" may result from the osteoblast functional defect noted in the patients described here.

In view of the clinical situation and the limitations of quantitative bone histology it is not surprising that the histological abnormalities were subtle. The patients underwent biopsy after clinical presentation with fractures, and by this time the rate of bone loss is usually slow $^{28}$ (in patients with an initially normal bone mass). Thus it is not surprising that resorbing and forming surfaces were roughly equivalent; the findings might be different in patients studied during the preclinical stage. Even were the biopsy specimen to be taken during a more active stage of bone loss, however, the imbalance between resorption and formation might be obscured by problems inherent in quantitative bone histology. One of these is the phenomenon of "coupling" by which osteoblasts appear at sites of previous osteoclastic resorption ${ }^{29}$ resulting in an approximate equivalence of forming and resorbing surfaces in human ${ }^{2630}$ and animal ${ }^{31}$ bone. In histological sections of bone it results in a large "blank" reading, which may obscure small imbalances between forming and resorbing surfaces. An additional limitation is that in human bone biopsy specimens it is not possible to directly measure resorption velocity, a parameter that varies widely in rats, ${ }^{32}$ and which could have a profound effect on total bone resorption in humans.

An unexpected finding was the presence of presumed healing microfractures in two of the 10 patients. These have been observed in vertebrae $e^{33}$ and femoral heads ${ }^{34}$ of elderly normal subjects, the numbers being increased when structural failure has subsequently occurred. ${ }^{24}$ They have not been noted in many hundreds of iliac biopsy specimens taken in this unit for other purposes. They are most likely to be indicative of local structural failure, and, though perhaps not unexpected, may be the first demonstration of this phenomenon in the ilium. Microfractures were seen in case 1 who had severe osteoporosis with widespread bone pain and in case 2 with relatively mild disease and bone pain only in the areas of vertebral collapse. These microfractures then are probably not a cause of symptoms.

This work was supported by the Department of Veterans' Affairs (Australia). We are grateful to Mrs V Macallister and Miss D Ivers for secretarial assistance.

\section{References}

1 Jowsey J, Kelly PJ, Riggs BL, Bianco AJ, Scholz DA, GershonCohen J. Quantitative microradiographic studies of normal and osteoporotic bone. J Bone Joint Surg 1965;47A:785-806.

2 Jowsey J, Johnson KA. Juvenile osteoporosis: bone findings in seven patients. J Pediatr 1972;81:511-17.

3 Bressot C, Meunier PJ, Chapuy MC, Lejeune E, Edouard C, Darby AJ. Histomorphometric profile, pathophysiology and reversibility of corticosteroid-induced osteoporosis. Metab Bone Dis Relat Res 1979;1:303-11.

4 Gallagher JC, Aaron J, Horsman A, Wilkinson R, Nordin BEC. Corticosteroid osteoporosis. Clin Endocrinol Metab 1973; 2:355-68.

5 Johnston CC, Norton J, Khairi MRA, et al. Heterogeneity of fracture syndromes in postmenopausal women. $J$ Clin Endocrinol Metab 1985;61:551-6.

6 Bordier PJ, Tun Chot S. Quantitative histology of metabolic bone disease. J Clin Endocrinol Metab 1972;1:197-215.

7 Francis RM, Peacock M, Aaron JE, et al. Osteoporosis in hypogonadal men: role of decreased plasma 1,25-dihydroxyvitamin $\mathrm{D}$, calcium malabsorption, and low bone formation. Bone 1986;7:261-8.

8 Bordier PJ, Miravet L, Hioco D. Young adult osteoporosis. J Clin Endocrinol Metab 1973;2:277-92.

9 Schenk RK, Olah AJ, Merz WA. Bone cell counts. In: Frame B, Parfitt AM, Duncan H, eds. Clinical aspects of metabolic bone disease. Amsterdam: Excerpta Medica, 1973:103-13.

10 Smith R. Idiopathic osteoporosis in the young. J Bone Joint Surg 1980;62B:417-27.

11 Parfitt AM, Mathews C, Rao D, Frame B, Kleerekoper M, Villanueva AR. Impaired osteoblast function in metabolic bone disease. In: DeLuca HF, Frost HM, Jee WSS, Johnston CC, Parfit AM, eds. Osteoporosis: recent advances in pathogenesis and treatment. Baltimore: University Park Press, 1981:321-30.

12 Jackson JA, Kleerekoper M, Parfitt AM, Rao DS, Villanueva AR, Frame B. Bone histomorphometry in hypogonadal and eugonadal men with spinal osteoporosis. J Clin Endocrinol Metab 1987;65:53-8. 
13 Whyte MP, Bergfeld MA, Murphy WA, Avioli LV, Teitelbaum SL. Postmenopausal osteoporosis. Am J Med 1982;72:193-202.

14 Gruber HE, Ivey JL, Thompson ER, Chesnut CH, Baylink DJ. Osteoblast and osteoclast cell number and cell activity in postmenopausal osteoporosis. Miner Electrolyte Metab 1986; 12:246-54.

15 Evans RA, Dunstan CR, Baylink DJ. Histochemical identification of osteoclasts in undecalcified sections of human bone. Miner Electrolyte Metab 1979;2:179-85.

16 Kaye M. When is it an osteoclast? J Clin Pathol 1984;37:398-400.

17 Dunstan CR, Evans RA. Quantitative bone histology: a new method. Pathology 1980;12:255-64.

18 Evans RA, Dunstan CR, Hills E. Bone metabolism in idiopathic juvenile osteoporosis: a case report. Calcif Tissue Int 1983; 35:5-8.

19 Jamshidi K, Swaim WR. Bone marrow biopsy with unaltered architecture: a new biopsy device. J Lab Clin Med 1971; 77:335-42.

20 Evans RA, Ashwell JR, Dunstan CR. Lack of metabolic bone disease in patients with fracture of the femoral neck. Aust NZJ Med 1981;11:158-61.

21 Sherrard DJ, Baylink DJ, Wergedal JE, Maloney NA. Quantitative histological studies on the pathogenesis of uremic bone disease. J Clin Endocrinol Metab 1974;39:119-35.

22 Nielsen HE, Melsen F, Christensen MS. Interrelationships between calcium-phosphorus metabolism, serum parathyroid hormone and bone histomorphometry in non-dialyzed and dialyzed patients with chronic renal failure. Miner Electrolyte Metab 1980;4:113-22.

23 Lips P, Courpron P, Meunier PJ. Mean wall thickness of trabecular bone packets in the human iliac crest: changes with age. Calcif Tissue Res 1978;26:13-17.

24 Todd RC, Freeman MAR, Pirie CJ. Isolated trabecular fatigue fractures in the femoral head. J Bone Joint Surg 1972;54B: 723-8.

25 Arlot M, Edouard C, Meunier PJ, Neer RM, Reeve J. Impaired osteoblast function in osteoporosis: comparison between calcium balance and dynamic histomorphometry. $\mathrm{Br}$ Med $\mathrm{J}$ 1984;289:517-20.

26 Evans RA, Flynn J, Dunstan CR, George CRP, McDonnell GD. Bone metabolism in chronic renal failure. Miner Electrolyte Metab 1982;7:207-18.

27 Evans RA, Marel GM, Lancaster EK, Evans M, Wong SYP. Bone mass is low in relatives of osteoporotic patients. Ann Intern Med 1988;104:870-3.

28 Chesnut $\mathrm{CH}$, Ivey JL, Gruber HE, et al. Stanozolol in postmenopausal osteoporosis: therapeutic efficacy and possible mechanisms of action. Metabolism 1983;32:571-80.

29 Parfitt AM. The coupling of bone formation to bone resorption: a critical analysis of the concept and of its relevance to the pathogenesis of osteoporosis. Metab Bone Dis Relat Res 1982;4:1-6.

30 Ivey JL, Baylink DJ. Postmenopausal osteoporosis: proposed roles of defective coupling and estrogen deficiency. Metab Bone Dis Relat Res 1981:3:3-7.

31 Thompson ER, Baylink DJ, Wergedal JE. Increases in number and size of osteoclasts in response to calcium or phosphorus deficiency in the rat. Endocrinology 1975;97:283-9.

32 Evans RA, Wergedal JE, Baylink DJ. Effect of dichloromethylene diphosphonate on bone metabolism in calcium and phosphorus-depleted rats. Miner Electrolyte Metab 1983;9:119-24.

33 Arnold JS. Focal excessive endosteal resorption in aging and senile osteoporosis. In: Barzel US, ed. Osteoporosis. New York: Grune and Stratton, 1970:80-100.

34 Wong SYP, Kariks J, Evans RA, Dunstan CR. Hills E. The effect of age on bone composition and viability in the femoral head. J Bone Joint Surg 1985;67A:274-83.

Requests for reprints to: Dr R A Evans, Metabolic Unit, Concord Hospital, Sydney, NSW 2139 Australia. 